\title{
EQUITY AND RESOURCES: AN ANALYSIS OF EDUCATION FINANCE SYSTEMS
}

\author{
Raquel Fernández \\ Richard Rogerson
}

Working Paper 7111

http://www.nber.org/papers/w7111

\author{
NATIONAL BUREAU OF ECONOMIC RESEARCH \\ 1050 Massachusetts Avenue \\ Cambridge, MA 02138 \\ May 1999
}

\begin{abstract}
We wish to thank Richard Romano and Eli Berman and seminar participants at the University of Iowa, University of Michigan, Boston University, and NYU as well as at the NBER Public Economics Conference on Education Finance and the Florida University Conference on Education Policy, for helpful comments. Both authors gratefully acknowledge financial support from their respective NSF grants and the first author also thanks the CV Starr Center for support. The views expressed herein are those of the authors and do not necessarily reflect the views of the National Bureau of Economic Research.

(C) 1999 by Raquel Fernández and Richard Rogerson. All rights reserved. Short sections of text, not to exceed two paragraphs, may be quoted without explicit permission provided that full credit, including ${ }^{\circ}$ notice, is given to the source.
\end{abstract}


Equity and Resources: An Analysis

of Education Finance Systems

Raquel Fernández and Richard Rogerson

NBER Working Paper No. 7111

May 1999

JEL No. H4, I2

\begin{abstract}
Over the last few decades many US states have made large changes to their systems of financing K-12 education with the explicit objective of providing more equitable educational opportunities. There has been relatively little accompanying analysis, however, examining how these changes might affect the total sum of resources dedicated to education and whether indeed increased equality is a likely outcome. We analyze five different education finance systems: local, State, foundation, power equalizing with recapture (PER) and power equalizing without recapture (PEN).

We find that finance systems can have very large effects on both resources devoted to education and equity. Our calibration suggests that total spending on education may differ by as much as $25 \%$ across systems. The trade-off between equity and resources, however, is not monotone. Although spending in a local system is typically greater than that in either the State system or PER, total spending is typically highest for the foundation and PEN systems, both of which reduce inequality of educational resources substantially relative to a local system.

We also rank systems in welfare terms by carrying out an expected utility calculation. We find that PER consistently ranks best, though it provides fewer resources to education than the foundation and PEN systems, and falls well short of the state system in terms of equity. Additionally, we find that the PER system is remarkably popular among these alternative finance systems--we prove analytically that for an important subset of preferences PER will win in majority voting comparisons with each of the other systems.
\end{abstract}

Raquel Fernández

Dept. of Economics

New York University

New York, NY 10003

and NBER

fernande@fasecon.econ.nyu.edu
Richard Rogerson

Dept. of Economics

University of Pennsylvania

Philadelphia, PA 19104

rogerson@econ.sas.upenn.edu 


\section{Introduction}

Publicly financed education is a pervasive feature of modern economies. Even a casual look at education spending patterns across either states within the US or across countries, however, reveals substantial variation in both spending on public education and its distribution across students. This may be thought to be in large part a result of the rules which impact on education spending-what we will call the education finance system.

Education finance systems differ significantly across states within the US as well as across countries, and are the subject of much controversy. Over the last few decades many US states have made dramatic changes to their systems of financing $\mathrm{K}-12$ education with the explicit objective of providing more equitable educational opportunities. There has been relatively little accompanying analysis, however, examining how these changes might affect the total sum of resources dedicated to education and whether indeed increased equality is a likely outcome.

Central to understanding how a school finance system affects the sum and distribution of education resources is an analysis of the mechanisms through which it transfers resources across individuals and distorts incentives to devote funds to education. The objective of this paper is to study these mechanisms in a simple general equilibrium model and to perform a calibration exercise to assess their quantitative significance. In order to do so we use a standard model of local public finance in which there are a large number of families that are heterogeneous with regard to income and are perfectly sorted into homogeneous communities. The education finance system sets down the rules that govern how revenues are raised and distributed across communities for education spending. A defining characteristic of our approach is that the key parameters of the education finance system are determined by a political economy system-in our case, by majority vote. This model seems the natural starting point for a comparison of systems. Its simplicity allows us to highlight the basic forces at work, yet is also hopefully rich enough to incorporate many of the elements essential to the issue.

The paper examines the implications of several prototypical education finance systems for resources devoted to education, their distribution across children, and welfare. Some of the questions we ask include, What are the trade-offs across systems between equity and efficiency? Is there a systematic relationship between resources devoted to education and equity? Which groups benefit and which lose when one system is adopted over another?

We analyze five different finance systems: local, State, foundation, power 
equalizing with recapture and power equalizing without recapture. A system of pure local finance involves no transfers of resources across districts; each district determines its own level of spending on education. In a pure State system, all students receive equal funding and districts are not allowed to increase spending over that level. A foundation system offers all districts a guaranteed minimum amount of support per student, but allows individual districts to tax themselves should they wish to supplement this guaranteed amount. In a power equalizing system with recapture (PER), districts use a common tax base to generate revenues for education. Hence, a given tax rate generates the same revenue for all districts, independent of the district's underlying characteristics. In a power equalizing system without recapture (PEN), districts with tax bases that exceed the specified common base use their own higher base to generate revenue for education.

We find that finance systems can have very large effects on both resources devoted to education and equity. Our calibration suggests that total spending on education may differ by as much as $25 \%$ across systems. The trade-off between equity and resources, however, is not monotone. While spending in a local system is typically greater than that in either the State system or in the power equalizing system with recapture, total spending is typically highest for the foundation and power equalizing without recapture systems, both of which reduce inequality of educational resources substantially relative to a local system.

We also rank systems in welfare terms by carrying out an expected utility calculation. Once again, the trade-off between total resources and equity is not simple. We find that the power equalizing system with recapture is consistently rated the best in this utility comparison, though it does not do as well in terms of total resources compared to foundation and PEN systems, and falls well short of the state system in terms of equity. Relative to a local system, PER offers roughly the same total resources but brings about a large reduction in inequality. Additionally, we find that the PER system is remarkably popular among these alternative finance systems-we prove analytically that for an important subset of preferences PER will win in majority voting comparisons with each of the other systems.

Our work is closely related to several papers. It builds directly on the work initiated by Inman (1978) who was among the first to carry out a quantitative comparison of education finance systems in the context of an explicit model. A key difference between his work and ours is that his abstracted from political economy issues. In using a political economy approach to contrast education finarice systems we continue the work begun in Fernandez and Rogerson (1995ab, 
1996, and 1998). Several others have also examined education finance issues using a political economy approach. Glomm and Ravikumar (1992) and Silva and Sonstelie (1995) contrast state and local finance systems, whereas Nechyba (1996) and de Bartolome (1997) study foundation systems. Epple and Romano (1996a) and Glomm and Ravikumar (1998) examine how private education affects spending on public education.

There is also a growing empirical literature devoted to examining how changes in state-level education finance systems affect education spending, including Downes and Shah (1994), Loeb (1998), Hoxby (1998), Evans, Murphy, Schwab (1997, 1998), Manwaring and Sheffrin (1997), and Card and Payne (1998). Hoxby's work is perhaps most relevant since she also focuses on the mechanics through which finance systems affect the incentives for individuals to spend on education. Her analysis, however, uses a reduced form empirical approach to understand how a given system with specified parameters will affect education spending. In contrast, our analysis stresses the general equilibrium interactions and the political economy issues that determine the key parameter settings within a given finance system. An advantage of the simplicity of our model is that it allows us to obtain analytical results and to do welfare comparisons of the various systems. This seems like an important first step before proceeding to ask how the incorporation of different factors, undoubtedly. significant in reality, affect our results.

Although their paper is not specifically on education finance, it is of interest to contrast our results with Epple and Romano (1996b). They consider the provision of a private good and examine three regimes: market provision only, government provision only, and government provision supplemented by the private market system. Although they have in mind a good such as health care which can be provided by the government yet supplemented privately, their framework is similar to ours. They assume that with any government intervention, majority vote decides the level of the proportional tax used to finance the private good, as do we. Thus, for the three systems in common in our analysis, we obtain the same theoretical results. Our theoretical analysis adds to theirs by examining two additional systems-PER and PEN-which are central to our welfare and majority voting results. In addition we focus on the issue of equity and, most importantly, we provide a quantitative assessment of the five systems.

An outline of the paper follows. In Section 2 we provide analytical characterizations of the five finance systems. Section 3 calibrates the model and provides a quantitative comparison of these systems. Section 4 examines the robustness of our conclusions. Section 5 concludes. 


\section{A Theoretical Analysis of Alternative Finance Systems}

\subsection{The Model}

The analysis of the effects of different financing systems is a complex undertaking. As noted previously, the impact of a particular education-finance system will in general depend upon the details of the system's rules and their interaction with the state and local tax systems, on the distribution of income, on the way in which tax rates, spending, and other key variables are chosen, on the distribution of employment, commercial property, and housing locations, etc. Here we choose to abstract away from many of these important elements in order to concentrate primarily on the interaction of the financing system with the distribution of income and the endogenous determination of the system's parameters.

The model we present is extremely simple. The economy consists of a continuum of agents, with population normalized to one, and with identical preferences over a private consumption good $c$ (the numeraire) and over the child's education, $q$. These preferences are given by

$$
u(c)+v(q)
$$

where $u$ and $v$ are both increasing and concave with $u^{\prime}(0)=v^{\prime}(0)=\infty{ }^{1}$

In order to calibrate our model, we will need to specify preferences. We will assume that these are given by

$$
\frac{c^{\alpha}}{\alpha}+A \frac{q^{\gamma}}{\gamma} \quad A>0, \alpha<0
$$

and when our more general preferences do not yield an unambiguous theoretical result, we will refer to these.

Agents are assumed to differ only in their initial endowment of income, $y_{i}$, whose cumulative distribution is described by $F(y)$, and whose mean, $\mu$, is assumed to be greater than its median, $\widetilde{y}$, i.e. $F(\mu)>0.5$.

The amount or quality of education received by a child is assumed to be solely a function of spending $(E)$ per student $(N)$ which, without loss of generality, we assume is linear, i.e.

\footnotetext{
${ }^{1}$ With the appropriate (single-crossing) assumptions, our results can easily be extended to more general preferences $U(c, q)$, where $U$ is strictly increasing and quasi concave. We present the case of separable preferences as it simplifies the algebraic exposition. We indicate throughout the assumptions required for the more general class of preferences.
} 


$$
q=\frac{E}{N}
$$

To focus the analysis on the different incentives associated with alternative school financing schemes, we assume that peer effects and parental attributes do not affect school quality. ${ }^{2}$ In order to further simplify matters, we restrict our attention to proportional taxation of income.

The consequences of a finance system are likely to depend on the degree of sorting of individuals into different districts. ${ }^{3}$ We focus on one extreme (which is standard in much of the public finance literature)-perfect sorting-which allows us to abstract from issues of distribution within a community in order to focus on distribution across communities. Thus, districts consist of individuals with the same level of income, implying no disagreement at the district level over the preferred levels of consumption and education. Each district $i$ therefore is associated with a level of income $y_{i}$. We assume that all children attend public schools in the district in which they live.

With the exception of a pure local finance system, the remaining education finance systems require the determination of key state level variables. For example, a foundation grant system requires the foundation amount to be determined, a state system requires that the level of funds devoted to education to be chosen, and both power equalizing systems require the common base to be specified. At a district level, how preferences vary across individuals is irrelevant in our model since perfect sorting implies no disagreement over district level variables. At the state level, however, different individuals will prefer different outcomes. Undoubtedly there is a complex political economy that aggregates individual preferences into a collective outcome. We have very little faith, however, in our knowledge and ability to model that reality. Instead, we follow what we consider to be a useful tradition in political economy, and attempt to capture some component of how heterogeneous preferences map into aggregate outcomes by assuming that these variables are determined by majority vote. We think that this serves as a useful benchmark.

\footnotetext{
${ }^{2}$ Several authors have studied peer effects. See de Bartolome (1990) for a survey of the empirical literature and a theoretical model incorporating peer effects. See also Benabou (1993, 1996), Durlauf (1995), Epple and Romano (1996a, 1998), and Caucutt (1997) for other studies incorporating peer effects.

${ }^{3}$ See Fernandez and Rogerson $(1996,1998 \mathrm{~b})$ and Fernandez (1997) for an analysis of local public finance systems with heterogeneous communties.
} 


\subsection{A Local Finance System}

This is a system with no redistribution. Although currently no state has a purely local system, local finance plays an important role in providing revenue for education and it is of interest to understand the implications of this extreme system. Furthermore, this system corresponds to Tiebout's (1956) model of public good provision in which (static) efficiency is achieved by individuals who "vote with their feet" so as to end up in homogeneous communities that tailor their provision of local public goods to exactly match the demands of their residents. ${ }^{4}$

In a local finance system, each district chooses a tax rate $t_{i}$ to fund the entirety of its education expenditures. Thus,

$$
\begin{aligned}
& q_{i}=t_{i} y_{i} \\
& c_{i}=\left(1-t_{i}\right) y_{i}
\end{aligned}
$$

where $t_{i}$ solves

$$
\max _{t_{i}} u\left(\left(1-t_{i}\right) y_{i}\right)+v\left(t_{i} y_{i}\right)
$$

Thus, each district's tax rate $t_{i}$ is given by the first-order condition:

$$
-u^{\prime}\left(y_{i}\left(1-t_{i}\right)\right)+v^{\prime}\left(t_{i} y_{i}\right)=0
$$

that equates the marginal utility from consumption to that from education.

It will be of interest further on to know how district tax rates depend on income. Using the implicit function rule on (2.6) yields:

$$
\frac{d t_{i}}{d y_{i}}=\frac{u^{\prime \prime} c_{i}-v^{\prime \prime} q_{i}}{\left(u^{\prime \prime}+v^{\prime \prime}\right) y_{i}^{2}}
$$

whose sign depends on $u^{\prime \prime} c_{i}-v^{\prime \prime} q_{i}$ which, for the preferences specified in (2.2), gives $\operatorname{sgn}\left(d t_{i} / d y_{i}\right)=\operatorname{sgn}(\gamma-\alpha)$. In our calibration we will focus our attention on the case of $\alpha=\gamma$, which implies an invariant district tax rate with a local finance system. $^{5}$

\footnotetext{
${ }^{4}$ Of course, no such perfectly stratified equilibrium may be possible since lower-income individuals may wish to reside with higher-income individuals for redistributional reasons. Segregation into homogenous communities may be obtained, however, by zoning and other restrictions (see Fernandez and Rogerson (1997a) and Hamilton(1975)).

${ }^{5}$ For the case of non-separable preferences, the sign of $d t_{i} / d y_{i}$ depends on the sign of $U_{c c} c-$
} 


\subsection{A State Finance System}

The extreme opposite of the local finance system is what we call the "State system". Under this system all districts receive the same per capita revenue for education and are restricted to using only these funds for education (equivalently, one may think of this as a system with only one district). For those who argue that equity is achieved only by providing equal resources for all children, this is the natural system to consider. ${ }^{6}$

Education spending is assumed to be financed by a proportional tax on income, $\tau_{s}$, so that

$$
\begin{aligned}
& c_{i}=\left(1-\tau_{s}\right) y_{i} \\
& q_{i}=q=\tau_{s} \mu
\end{aligned}
$$

We assume that $\tau_{s}$ is the outcome of majority vote (i.e. $\tau_{s}$ must be preferred to any other tax rate in a pair-wise comparison by at least $50 \%$ of the voters).

To determine the majority-vote equilibrium value of the tax rate we need to understand how individual preferences vary over this variable. An individual's preferred tax rate is the solution to:

$$
\max _{\tau_{s}} u\left(\left(1-\tau_{s}\right) y_{i}\right)+v\left(\tau_{s} \mu\right)
$$

yielding the first-order condition

$$
-u^{\prime}\left(\left(1-\tau_{s}\right) y_{i}\right) y_{i}+v^{\prime}\left(\tau_{s} \mu\right) \mu=0
$$

As indicated by $(2.10)$, the State system changes the implicit relative price of education from one to $y_{i} / \mu$, i.e. the relative price now increases with individual income.

Note that individual preferences are single-peaked in $\tau_{s}$, ensuring the existence of a majority-voting equilibrium. To determine the identity of the median (and hence decisive) voter, we need to know how the preferred tax rate varies with income. Using the implicit function rule on (2.10) yields:

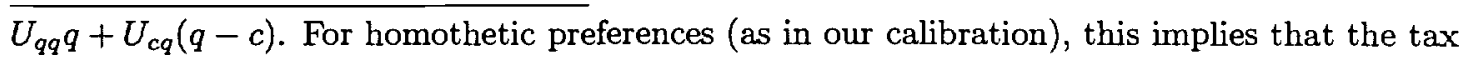
rate is invariant across districts.

${ }^{6}$ California's landmark State Supreme Court ruling against the constitutionality of its previous (foundation) system in combination with Proposition 13 led to the adoption of this type of system (see Fernandez and Rogerson (1995a) and Silva and Sonstelie (1995) for an analysis). 


$$
\frac{d \tau_{s}}{d y_{i}}=\frac{u^{\prime \prime} c_{i}+u^{\prime}}{u^{\prime \prime} y_{i}^{2}+v^{\prime \prime} \mu^{2}}
$$

whose sign is that of $-\left(u^{\prime \prime} c+u^{\prime}\right)$. For the preferences specified in (2.2), this expression is given by $-\alpha c^{\alpha-1}$ which is positive given our assumption of $\alpha<$ $0 .^{7}$ Note that our assumption on preferences implies that indifference curves are single-crossing in $(\tau, q)$ space and that the slopes of these curves are increasing in income (henceforth we will use the acronym ISC to refer to this characteristic). This turns out to be an extremely useful property. It implies that if an individual with income $y_{i}$ prefers a $(\tau, q)$ bundle to another $\left(\tau^{\prime}, q^{\prime}\right)$, and if $\tau>\tau^{\prime}$ and $q>q^{\prime}$, then all individuals with $y>y_{i}$ prefer the first bundle as well. If, on the other hand, the first bundle has a lower $\tau$ and $q$, then all individuals with $y<y_{i}$ prefer it to $\left(\tau^{\prime}, q^{\prime}\right)$. Henceforth the assumption the preferences satisfy ISC (as they do for the preferences specified in (2.2)) will be maintained.

Thus, the equilibrium tax rate must satisfy (2.10) for the voter with the median income level, i.e., $y_{i}=\tilde{y}$. The median voter's ability to tax mean income rather than her own lower income implies that in equilibrium she (and all other agents with income lower than the median) will obtain a greater $q$ under a State relative to a local system. This does not imply that these individuals are better off under a State system, as the median voter will be imposing her own preferred (and higher, given 2.2) tax rate rather than the rates preferred by lower-income individuals. The median voter thougk, and by continuity those in some interval around the median, will be better off. Another implication is that all individuals with income higher than the mean will be worse off in a State relative to a local system. Not only do these individuals not obtain their preferred tax rate, but they must also tax a lower base than their own. Again, continuity implies that there will be an interval of individuals with income lower than the mean that strictly prefer the local system to the State finance system.

\subsection{A Foundation System}

Many state constitutions contain clauses requiring them to guarantee an "acceptable" minimum level of education for all its residents. Foundation systems are a natural attempt to deal with this responsibility. In this system districts are

\footnotetext{
${ }^{7}$ For non-separable preferences, the sign of (2.11) is given by the sign of $U_{q c}(1-\tau) \mu-U_{c}-U_{c c} c$. Requiring this to be positive is equivalent to requiring the slope of indifference curves (in $(\tau, q)$ space) to be increasing in income.
} 
required to tax at some minimum level, $\tau_{f}$, in exchange for some guaranteed base level of expenditures per student-the foundation grant $f$. We assume that this tax is used to fund the foundation grant, yielding

$$
f=\tau_{f} \mu
$$

Unlike in the State system, however, a district can choose to augment its education expenditures by further taxing its own district income. Thus, letting $t_{i}$ denote the district level tax, we have: ${ }^{8}$

$$
\begin{aligned}
& c_{i}=\left(1-t_{i}-\tau_{f}\right) y_{i} \\
& q_{i}=f+t_{i} y_{i}
\end{aligned}
$$

As in the State system, the foundation tax rate (and thus the foundation grant level) is chosen by majority vote. We assume that tax rate decisions are made in two stages. In the first stage, majority vote at the state level determines the foundation tax. In the second stage, districts make their district tax choice.

To solve for the equilibrium tax rates we start with the district tax decision. Given a state-wide foundation tax rate outcome, $\tau_{f}$, a district's preferred tax rate is the solution to:

$$
\max _{t_{i}} u\left(\left(1-t_{i}-\tau_{f}\right) y_{i}\right)+v\left(\tau_{f} \mu+t_{i} y_{i}\right), \quad t_{i} \geq 0
$$

yielding the first-order condition

$$
-u^{\prime}\left(\left(1-t_{i}-\tau_{f}\right) y_{i}\right) y_{i}+v^{\prime}\left(\tau_{f} \mu+t_{i} y_{i}\right) y_{i} \leq 0
$$

with strict equality for $t_{i}>0$.

Next, we find the state-wide foundation tax by solving for an individual's preferred tax rate as a function of individual income, i.e., we solve:

$$
\max _{\tau_{f}} u\left(\left(1-t_{i}\left(\tau_{f}\right)-\tau_{f}\right) y_{i}\right)+v\left(\tau_{f} \mu+t_{i}\left(\tau_{f}\right) y_{i}\right), \quad \tau_{f} \geq 0
$$

yielding the first-order condition:

$$
-u^{\prime} y_{i}+v^{\prime} \mu+\left(-u^{\prime}+v^{\prime}\right) y_{i} t_{i}^{\prime} \leq 0
$$

\footnotetext{
${ }^{8}$ See de Bartolome (1997) for an alternative formulation of a foundation system.
} 
which, using (2.15) gives:

$$
\left.-u^{\prime}\left(1-t_{i}-\tau_{f}\right) y_{i}\right) y_{i}+v^{\prime}\left(\tau_{f} \mu+t_{i} y_{i}\right) \mu \leq 0
$$

with strict equality for $\tau_{f}>0$.

Note that if an individual's preferred foundation tax is positive (i.e. $u^{\prime} y_{i}=$ $v^{\prime} \mu$ ), then (2.15) can only be satisfied for $y_{i}<\mu$. So, individuals with income greater than the mean must have a preferred foundation tax rate of zero. A similar argument can be used to show that all individuals with income lower than the mean have a preferred district tax rate of zero (conditional upon obtaining their preferred foundation tax rate).

The intuition for the above results is clear: All individuals with income below the mean prefer to finance their education entirely via the foundation grant (in fact, these individuals' preferred foundation tax rate is the same as their preferred tax rate under the state system). This redistributes from those with income above the mean to those below the mean. Individuals with income greater than the mean, on the other hand, prefer zero redistribution and to finance their education solely via the district tax (i.e., their preferred foundation tax rate is zero and, were they to obtain this tax, their district tax would be the same as under a local system). ${ }^{9}$

The fact that preferred foundation tax rates are the same as preferred State system tax rates for all individuals with income below the mean (and zero for all those above the mean) implies that the median voter under a foundation system is of lower income then the median voter in the State system; all individuals with income greater than the mean have preferred tax rates of zero and for all others the preferred foundation tax is increasing in income. Consequently, the median voter in this system, $\widetilde{y}_{f}$, is determined by

$$
F(\mu)-F\left(\tilde{y}_{f}\right)=.5
$$

Which system will generate greater expenditures on education-Foundation or State? The foundation system clearly will have lower per capita state government expenditures (i.e., foundation grant level) than under a State system, i.e., $\tau_{f}<\tau_{s}$. This follows from the fact that the foundation median voter has lower income than the State system median voter, implying a lower preferred tax rate on mean

\footnotetext{
${ }^{9}$ The logic of this result does not depend on any particular specification of preferences.
} 
income..$^{10}$ Thus, poorer individuals will have lower expenditures on education under the foundation system. Total expenditures under the State system need not be greater, however, since the foundation system allows topping up, which the State system does not. Thus, a priori, which system dedicates greater resources to education is ambiguous.

To determine which individuals will choose to top up the equilibrium foundation grant with district spending, note first that all individuals with income lower than $\widetilde{y}_{f}$ will set $t_{i}=0$. Furthermore, all individuals with $y_{i} \geq \widetilde{y}_{f}$ but smaller than some level $\hat{y}$, find the foundation tax rate lower than what they would prefer but nonetheless are unwilling to supplement the foundation grant with additional district taxation (since for them $u^{\prime}>v^{\prime}$ ). Lastly, all individuals with income greater than $\hat{y}$ will set a positive district tax as given by (2.15) (with strict equality). The income level $\hat{y}$ is implicitly defined by:

$$
u^{\prime}\left(\left(1-\tau_{f}\right) \widehat{y}\right)=v^{\prime}\left(\tau_{f} \mu\right)
$$

where $\tau_{f}$ solves (2.18) (with strict equality) for $y_{i}=\widetilde{y}_{f}$.

Proposition 1. Topping up begins at an income level lower than the mean, i.e., $\hat{y}<\mu$.

Proof: In equilibrium, $u^{\prime}\left(\widehat{y}\left(1-\tau_{f}\right)\right)=v^{\prime}\left(\tau_{f} \mu\right)$. Now, for all $y>\widetilde{y}_{f}$, were their expenditures on education solely the foundation grant, these individuals would have $u^{\prime}\left(y\left(1-\tau_{f}\right)\right) y<v^{\prime}\left(\tau_{f} \mu\right) \mu$. Combining these two expression yields $u^{\prime}\left(\widehat{y}\left(1-\tau_{f}\right)\right) \widehat{y} / \mu<u^{\prime}\left(\widehat{y}\left(1-\tau_{f}\right)\right)$, which is feasible only if $\widehat{y}<\mu . \|$

Who prefers a foundation system to a State or local system? Individuals with income below $\widetilde{y}_{f}$ (and an interval of individuals above this level) prefer the foundation system to the State system. Both systems redistribute by taxing mean income, but the foundation system has a state-level tax rate closer to their preferred one since $\widetilde{y}_{f}<\tilde{y}$ implies $\tau_{f}<\tau_{s}$. The opposite preferences hold for individuals with income in an interval around $\tilde{y}$. All individuals with income greater than the mean share the same preferences: they prefer the foundation

\footnotetext{
${ }^{10}$ In fact, as demonstrated by Epple and Romano (1996b), independently of how preferred tax rates vary with income, government expenditures will always be at least as large in a government only system. In comparison with a State system, under a foundation system all voters with income greater than the mean have a preferred tax of zero (i.e. lower than before), whereas the preferences of all other individuals are unchanged. Thus, the median voter will have either the same or a lower preferred tax rate.
} 
system as it imposes a lower state tax rate (i.e., less redistribution) than the State system and allows them to top up. Below we show formally that a majority of individuals prefer the foundation system to either local or State.

Proposition 2. A majority of individuals prefer a foundation to a State or local system.

Proof: Consider first the vote between a foundation and a State system. All individuals with $y_{i} \geq \mu$ strictly prefer a foundation system as it would allow them to obtain the same $q$ as under the state system but more cheaply given that $\tau_{f}<\tau_{s}$ and $y_{i} \geq \mu$. Furthermore, all individuals with $y_{i} \leq \widetilde{y}_{f}$ strictly prefer the foundation system, since by revealed preference $\widetilde{y}_{f}$ prefers the bundle $\left(\tau_{f}, f\right)$ to $\left(\tau_{s}, q_{s}\right)$ and, given that the first bundle is smaller in both components than the second, ISC implies that this ranking is shared by all individuals with income lower than $\widetilde{y}_{f}$. Since $1-F(\mu)+F\left(\widetilde{y}_{f}\right)=.5$, continuity of preferences and income implies that more than $50 \%$ of the population prefers a foundation to State.

Consider next the vote between a foundation and a local system. Note that a possible outcome under a foundation system is $\tau_{f}=0$, i.e., the equivalent of a pure local system. Thus, the choice of a strictly positive $\tau_{f}$ in a foundation system allows us to conclude that by revealed preference, a majority must strictly prefer a foundation system to a local system. ${ }^{11}||$

\subsection{A Power Equalizing with Recapture System (PER)}

Several court cases have challenged existing education finance systems by noting that unequal district tax bases gives rise to unequal access to education, the equality of which they argue their State constitution guarantees. In particular, they have argued that equal access to education cannot be obtained if districts that tax at the same rate obtain unequal resources. Power equalizing systems, originally introduced into the education finance debate by Coons et al. (1970), were the natural outgrowth of this argument. These systems give districts access to the same tax base. In this section we explore the implications of a power equalizing system with recapture (PER henceforth) in which the tax base is determined endogenously and all districts are required to tax this common base (unlike a system without recapture, which we explore in the next section).

In a PER system, each district finances education by taxing its own base at some chosen rate $t_{i}$. The revenue generated by doing so is independent of the

\footnotetext{
${ }^{11}$ See also Epple and Romano (1996b).
} 
district's tax base, however, and instead is determined by the level of the common tax base $z_{R}$. Thus,

$$
q_{i}=t_{i} z_{R}
$$

The difference between aggregate expenditures on education and the amount raised by each district is assumed to be funded by a state-wide $\operatorname{tax} \tau_{R}$ on income. Thus $\tau_{R}$ must satisfy:

$$
\tau_{R} \mu=\int_{i} t_{i}\left(z_{R}-y_{i}\right) f\left(y_{i}\right) d i
$$

with private consumption in each district given by:

$$
c_{i}=\left(1-t_{i}-\tau_{R}\right) y_{i}
$$

Note that the state tax need not be positive (i.e., (2.22) may imply a negative tax rate) since districts with income greater than $z_{R}$ contribute a net positive amount of $t_{i}\left(y_{i}-z_{R}\right)$ to the funds available for other districts. This is slightly problematic since it raises the issue (absent in other systems) of what should be done with the potentially excess funds. One possibility is to redistribute these funds in proportion to individual income. While we report on the result of such a scheme further on, we were more persuaded by the alternative approach of constraining individuals to tax bases that yield a non-negative $\tau_{R}$. This has the attractive feature of ensuring that the choice of tax base is not the result of the desire to redistribute income for private consumption rather than for education (the latter being the focus of our study), i.e., it ensures that individuals do not choose a low tax base so as to obtain a negative state income tax rate. Hence, we impose $\tau_{R} \geq 0$.

As in the foundation case, we can think of choices being made in two stages. In the first stage, agents vote on the level of the common tax base. In the second stage, districts choose their tax rates. Thus, individuals face the following maximization problem:

$$
\begin{gathered}
\max _{z, t_{i}} u\left(\left(1-t_{i}-\tau_{R}\right) y_{i}\right)+v\left(t_{i} z_{R}\right) \\
\text { s.t. } \quad(2.22) \text { and } \tau_{R} \geq 0
\end{gathered}
$$

yielding, after some substitutions, the first-order conditions:

$$
-u^{\prime}\left(\left(1-t_{i}-\tau_{R}\right) y_{i}\right) y_{i}+v^{\prime}\left(t_{i} z_{R}\right) z_{R}=0
$$




$$
v^{\prime}\left(t_{i} z_{R}\right)\left[-z_{R} \tau_{R}^{\prime}+t_{i}\right] \leq 0
$$

where (2.26) is a strict equality if $\tau_{R}>0$. The first equation gives an individual's district income tax for any given tax base level. ${ }^{12}$ The second gives the individual's preferred tax base level subject to the requirement that the state income tax implied by that base be non-negative. Note that (2.26) incorporates information obtained from (2.25) and that calculating $\tau_{R}^{\prime}$ requires use of (2.22) and (2.25).

Using the implicit function rule on (2.25) we can find how, for a given $z_{R}$, the district tax rate varies with income:

$$
\frac{d t_{i}}{d y_{i}}=\frac{u^{\prime \prime} c_{i}+u^{\prime}}{u^{\prime \prime} y_{i}^{2}+v^{\prime \prime} z_{R}^{2}}
$$

implying, as with the preferred state tax rate under the State system, that district tax rates are increasing in income.

We cannot guarantee that our preferences are single peaked in $z_{R}$. We are assured, nonetheless, of the existence of a majority vote equilibrium since preferences can be shown to be single crossing in $\left(\tau, z_{R}\right)$ space. To see this, note that the slope of an individual's indifference curves is given by

$$
\left.\frac{d \tau}{d z_{R}}\right|_{u_{i}}=\frac{v^{\prime}\left(t_{i} z_{R}\right) t_{i}}{u^{\prime} y_{i}}>0
$$

and differentiating (2.28) with respect to $y$ yields after using (2.27), (2.25), and some algebra:

$$
\frac{\partial\left(\frac{d \tau}{d z_{R}} \mid u_{i}\right)}{\partial y_{i}}=\frac{\frac{d t_{i}}{d y_{i}}}{u^{\prime 2} y_{i}^{2}} v^{\prime} u^{\prime} y_{i}>0
$$

Thus any two indifference curves of any two individuals with different incomes cross only once, and the slope of an indifference curve through any $\left(\tau, z_{R}\right)$ point is increasing in income. This guarantees that the individual with median income is the decisive voter since any greater and feasible $\left(\tau, z_{R}\right)$ bundles would be blocked by those $50 \%$ with income lower than the median and any smaller and feasible bundle would be blocked by those $50 \%$ with income greater than the median. ${ }^{13}$

\footnotetext{
${ }^{12}$ Note that when choosing a district tax rate, the individual ignores the effect of this on $\tau_{R}$ since any one district's choice has a negligible effect on the total funds needed.

${ }^{13}$ See Roberts (1977) and Meltzer and Richard 1981).
} 
For many specifications, preferences are sufficiently single-peaked with respect to $z_{R}$ so that if a majority of individuals are effectively constrained in their preferred value of $z_{R}$ by the non-negativity restriction on the state tax rate, the outcome of majority vote will be $z_{R}=z^{*}$ where $z^{*}$ solves

$$
\int_{i} t_{i}\left(z^{*}-y_{i}\right) f\left(y_{i}\right) d i=0
$$

Proposition 3. $z^{*}>\mu$.

Proof: Let $t_{i}$ be $y_{i}$ 's choice of district tax rate given a tax base of level $z$, with $t_{z}$ being the rate chosen by an individual with income $y_{i}=z$. Note that any individual with income $y_{i}<z$ is imposing a burden on taxpayers of the amount $t_{i}\left(z-y_{i}\right)$; any individual with $y_{i}>z$ is reducing the burden on taxpayers by the amount $t_{i}\left(y_{i}-z\right)$. Hence,

$$
\begin{aligned}
\tau_{R} \mu & =\int_{\underline{y}}^{z} t_{i}\left(z-y_{i}\right) f\left(y_{i}\right) d i-\int_{z}^{\bar{y}} t_{i}\left(y_{i}-z\right) f\left(y_{i}\right) d i \\
& <\int_{\underline{y}}^{z} t_{z}\left(z-y_{i}\right) f\left(y_{i}\right) d i-\int_{z}^{\bar{y}} t_{z}\left(y_{i}-z\right) f\left(y_{i}\right) d i \\
& =t_{z}(z-\mu)
\end{aligned}
$$

which is non-positive if $z \leq \mu$. The strict inequality follows from our assumption on preferences that guarantees that district tax rates are increasing in income (see 2.27). ${ }^{14}$ Thus, for $z \leq \mu$, it follows that $\tau_{R}<0$ and thus $z^{*}>\mu$.\|

Proposition 4. PER is preferred by a majority over a State system.

Proof: Note that $\left(z_{R}=z^{*}, \tau_{R}=0\right)$ is a feasible outcome under PER. Furthermore, it is preferred by all to the equilibrium outcome under a State system since $z^{*}>\mu, \tau_{R}<\tau_{s}$ implies that any individual can obtain $q_{s}$ under PER more cheaply than under the State system. Now, the equilibrium bundle $\left(z^{*}, \tau_{R}\right)$ is by revealed preference majority preferred to $\left(z^{*}, 0\right)$. By transitivity, therefore, PER is preferred by a majority to a State system.||

\footnotetext{
${ }^{14}$ Note that any preferences that imply indifference curves whose slope is increasing in income in $\left(t_{i}, q\right)$ space, i.e. any preferences that satisfy the condition in footnote (??), yield $\frac{d t_{i}}{d y_{i}}>0$.
} 
Proposition 5. If in equilibrium $z_{R}=z^{*}$, then PER is preferred by a majority to a local or foundation system.

Proof: All individuals with $y_{i}<z^{*}$ (i.e., a majority) prefer PER to a foundation or local system as PER allows them to obtain the same $q$ as under either of those systems but at a lower cost given that $z^{*}>y_{i}$ implies that they can tax a higher tax base than their own at a zero state income tax (since $\tau_{R}=0$ ). $\|$

We cannot extend the result above to the case of an unconstrained outcome (i.e., $z_{R}>z^{*}, \tau_{R}>0$ ) under PER, however. Although by revealed preference a majority prefers the equilibrium bundle to $\left(z^{*}, 0\right)$, this may not be the same majority that prefers $z^{*}$ to a foundation or to a local system. In fact, ISC guarantees that all individuals with $y_{i} \geq \widetilde{y}$ prefer the equilibrium bundle to $\left(z^{*}, 0\right)$, but we can only be sure that individuals with $y_{i} \leq z^{*}$ prefer $\left(z^{*}, 0\right)$ to either the foundation or local system. Therefore a transitivity argument cannot be used as was done in the case of Proposition 4. Note that a foundation system may be preferred to PER by relatively wealthy individuals since it allows them to tax their own income (rather than lower common tax base) to obtain additional resources for education over the common foundation grant level. Individuals with income lower than the median, on the other hand, may prefer the foundation system over PER despite the lower tax base and the uniform tax rate, since the state tax rate under PER may be too high. Similarly, because of the state tax burden in PER, it can no longer be argued that all those with income below $z^{*}$ must prefer PER over a local system.

In our calibration we end up specifying preferences as $\frac{c^{\alpha}}{\alpha}+A_{\alpha}^{q^{\alpha}}, \alpha<0$. For these preferences, for the large variety of $\alpha$ values we experimented with, the equilibrium outcome under PER is always constrained yielding $z_{R}=z^{*}$ (i.e., $\tau_{R}=0$ ). Hence, were individuals with these preferences given to choose among the four education finance systems discussed so far, propositions 4 and 5 imply that a majority would favor PER over all others.

It is also of interest to examine how each $q_{i}$ will differ across systems for this family of preferences. Given that the tax base under PER will be $z^{*}$ (i.e., $\tau_{R}=0$ ) which is greater than the tax base of $\mu$ available under the State system, it follows that all individuals with income greater than some $y^{\prime}, y^{\prime}<\tilde{y}$, will obtain a greater $q_{i}$ under PER than under a State system. Comparing PER with a foundation system, $z_{R}>\mu$ implies all $y_{i} \in\left[\tilde{y}_{f}, z^{*}\right]$ obtain a greater $q_{i}$ under PER, as do an interval of individuals with income lower than $\widetilde{y}_{f}$ and an interval with income greater than $z^{*}$. Relative to a local system, all individuals with $y_{i}<z^{*}$ will have 
a greater $q_{i}$ under PER; all those with income greater than $z^{*}$ will have a greater $q_{i}$ under the local system.

\subsection{A Power Equalizing System with No Recapture (PEN)}

Lastly, we turn to an analysis of a power equalizing system that, unlike the previous case, allows individuals with income greater than the common base to tax their own income, so that

$$
q_{i}=\left\{\begin{array}{cc}
t_{i} z_{N} & y_{i} \leq z_{N} \\
t_{i} y_{i} & y_{i}>z_{N}
\end{array}\right.
$$

where $z_{N}$ is the common tax base. This system (PEN hereafter) is somewhat of a hybrid between the foundation system and the PER system, in that while it does not guarantee any particular level of education spending per student, it does guarantee the tax base which districts can use to generate education spending.

We assume, as in the previous case, that the required education funds are generated by a state income tax, $\tau_{N}$, so that private consumption is given by:

$$
c_{i}=\left(1-t_{i}-\tau_{N}\right) y_{i}
$$

and the state tax rate must satisfy the budget constraint:

$$
\tau_{N} \mu=\int_{y_{i}<z_{N}} t_{i}\left(z_{N}-y_{i}\right) f\left(y_{i}\right) d i
$$

Note that, unlike the previous case, $\tau_{N}$ is strictly positive for any $z_{N}>y$ since higher-income individuals no longer automatically redistribute simply by taxing themselves to provide for their own education.

As before, we can think of the choice over $z_{N}$ and $t_{i}$ as occurring in two stages, with majority vote over $z_{N}$ followed by individual choice over the district tax rate. Individuals therefore face the following maximization problem:

$$
\begin{array}{r}
\max _{z_{N}, t_{i}} u\left(\left(1-t_{i}-\tau_{N}\right) y_{i}\right)+v\left(t_{i} \max \left\{z_{N}, y_{i}\right\}\right) \\
\text { s.t. } \quad \tau_{N} \mu=\int_{y_{i}<z_{N}} t_{i}\left(z_{N}-y_{i}\right) f\left(y_{i}\right) d i
\end{array}
$$

The maximization problem over $t_{i}$ is not problematic; it simply depends on whether the (at that stage given) value of $z_{N}$ is greater or smaller than the individual's district income. Thus, the first-order conditions are: 


$$
-u^{\prime}\left(\left(1-t_{i}-\tau_{N}\right) y_{i}\right) y_{i}+v^{\prime}\left(t_{i} y_{i}\right) y_{i}=0, \quad y_{i} \geq z_{N}
$$

and

$$
-u^{\prime}\left(\left(1-t_{i}-\tau_{N}\right) y_{i}\right) y_{i}+v^{\prime}\left(t_{i} z_{N}\right) z_{N}=0, \quad y_{i}<z_{N}
$$

Unfortunately, the maximization problem over $z_{N}$ is generally not single peaked. Even if the state income tax rate is convex in $z_{N}$, individuals will tend to have a local maximum at $z_{N}=\underline{y}$ (or equivalently at $z_{N}=0$ ) and at some $z_{N}>y_{i}$. Thus, the existence of a majority vote equilibrium is not guaranteed, although for all the parameter values we study equilibrium always exists. The first-order condition for an interior maximum for $z_{N}$ yields, after substituting (2.36),

$$
v^{\prime}\left(t_{i} z_{N}\right)\left[-\tau_{N}^{\prime} y_{i}+t_{i}\right]=0
$$

where calculating $\tau_{N}^{\prime}$ requires (2.33), (2.35) and (2.36). It is easy to show that $\tau_{N}$ is increasing in $z_{N}$.

Proposition 6. A majority of individuals (weakly) prefer PEN to a local system.

Proof: Note that a feasible outcome under PEN is $z_{N}=\underline{y}$ which is equivalent to a system with no redistribution, i.e., a local system. ${ }^{15}$ Hence any outcome $z_{N}>\underline{y}$ indicates that a majority strictly prefers PEN to a local system and an outcome of $z_{N}=\underline{y}$ indicates that a majority is indifferent.||

For the same common tax base level of $z_{R}=z_{N}=z$ (given $z<\bar{y}$ ), the state tax rate required to fund education expenditures is greater under PEN than under PER. To see this, note that (2.25) and (2.36) imply that when faced with the same common tax base $z$, were the state tax the same under both systems, all individuals with $y_{i} \leq z$ would choose the same district tax rates under both systems. Since under PER individuals with $y_{i}>z$ contribute to the funds available whereas under PEN they do not, it follows from concavity of the utility function that $\tau_{R}(z)<\tau_{N}(z)$. (where $\tau_{j}(z)$ indicates the state tax rate required to fund education under system $j, j=(\mathrm{PER}, \mathrm{PEN})$, given a tax base of $z$ ).

For the proposition that follows, it is important to note that if faced with a choice between $\left(z_{R}, \tau_{R}\right)$ under PER and $\left(z_{N}, \tau_{N}\right)$ under PEN, then all individuals

\footnotetext{
${ }^{15}$ Note that all values of $z_{N} \in[0, \underline{y}]$ are equivalent; they all imply no redistribution and a state tax rate of zero.
} 
with $y_{i} \leq \min \left\{z_{R}, z_{N}\right\}$ need compare only the utility that they obtain from each bundle to determine which system they prefer. By way of contrast, the preferences of individuals with $y_{i}>\min \left\{z_{R}, z_{N}\right\}$ depend not solely on the two bundles but also on the system, as PEN allows them to tax their own income whereas PER does not.

Proposition 7. A majority of individuals prefer PER over PEN if $z_{N} \geq z_{R}$.

Proof: To begin, note that if $\min \left\{z_{N}, z_{R}\right\} \geq \bar{y}$, then these systems are equivalent and hence must have $z_{N}=z_{R}$; thus all would be indifferent between the two systems. If $\min \left\{z_{N}, z_{R}\right\}<\bar{y}$, note first that $z_{N} \geq z_{R}$ implies $\tau_{N}>\tau_{R}\left(z_{N}\right) \geq \tau_{R}\left(z_{R}\right)$. But under a PER system, by revealed preference, the median voter (weakly) prefers $\left(z_{R}, \tau_{R}\right)$ to $\left(z_{N}, \tau_{R}\left(z_{N}\right)\right)$. Since the first bundle is weakly smaller in both components than the second, ISC implies that all individuals with $y_{i} \leq \tilde{y}$ also prefer $\left(z_{R}, \tau_{R}\left(z_{R}\right)\right)$ to $\left(z_{N}, \tau_{R}\left(z_{N}\right)\right)$. But $\left(z_{N}, \tau_{R}\left(z_{N}\right)\right)$ is strictly preferred by all to obtaining, under PER, $\left(z_{N}, \tau_{N}\right)$. Since for all $y_{i}<z_{R}$ only the choice of bundles matters, this implies that at least $50 \%$ of individuals strictly prefer PER to PEN. ${ }^{16} \|$

It is also easy to show that a majority of individuals prefer PER to PEN if the outcome under PER is $z^{*}$.

Proposition 8. A majority of individuals prefer PER over PEN if $z_{R}=z^{*}$.

Proof: By Proposition 7, if $z_{N} \geq z^{*}$, PER is majority preferred to PEN. If, on the other hand, $z_{N}<z^{*}$, all individuals with $y_{i} \leq z^{*}$ prefer PER to PEN since the former allows them to obtain the same $q_{i}$ as under PEN but at a lower cost since $z_{N}<z^{*}$ and $\tau_{N} \geq \tau_{R}=0$. Since $z^{*}>\mu$, these individuals are more than $50 \%$ of the population. $\|$

Hence, we have shown that PER is majority preferred to PEN for all cases save if $z_{N}<z_{R}, z_{R} \neq z^{*}$, and $\tau_{R}>\tau_{N}$. In such a case PEN may be preferred to PER. To see why note that we can no longer use the single-crossing logic to argue that all individuals with $y_{i}>\tilde{y}$ would prefer $\left(z_{R}, \tau_{R}\right)$ under PER to $\left(z_{N}, \tau_{N}\right)$ under PEN. Some of these individuals are able to tax their own base under PEN and not under PER. Consequently, for these individuals a simple comparison of the two bundles that ignores the system that generated them is insufficient. For

\footnotetext{
${ }^{16}$ Note that the logic of this argument is independent of whether the choice under PER is constrained by the non-negativity requirement.
} 
the purposes of our quantitative work, this ambiguity is not problematic since our calibrations always yield $z_{R}=z^{*}$, and hence PER is majority preferred to PEN by Proposition 8 .

\section{Quantitative Results}

In this section we report the results of a quantitative comparison of the five education-finance systems. As discussed in the previous section, each finance system has distinct implications for total spending on education and its distribution across students. Our objective is to obtain some sense for how large these differences might be in a reasonably parameterized version of the model.

\subsection{Functional Forms and Parameter Values}

We begin by choosing functional forms and assigning parameter values. The model's structure is extremely parsimonious-we need to specify only the distribution of income and preferences over consumption and quality of education.

One possible choice for the income distribution is to use households' income distribution for a typical year. If one interprets the model-period as corresponding to the entire schooling period of a child, however, then presumably it is income over a longer time span that is relevant to the decision makers. Of course, if parents are unable to borrow against their own future income then some measure in between annual and lifetime income is the correct one. Rather than take a stand on the degree of imperfection in the capital market, we use lifetime income and later report results using annual income in our section on sensitivity.

Fullerton and Rogers (1993) estimate the distribution of lifetime household income for the US using data from the PSID for the years 1970-1987. They compute mean lifetime income for each decile (subdividing the lowest and highest deciles each into two groups) for both pretax income as well as income net of taxes and transfers. We used both measures in our analysis, but found that the results did not differ in any significant way. Consequently, we only report results for the case of income net of taxes and transfers. Table 1 displays the income distribution. 
Table 1

Lifetime Income Distribution

Percentile Mean Lifetime Income

(000's of 1986 dollars)

$\begin{array}{cc}0-2 & 217 \\ 2-10 & 355 \\ 10-20 & 433 \\ 20-30 & 515 \\ 30-40 & 565 \\ 40-50 & 665 \\ 50-60 & 735 \\ 60-70 & 814 \\ 70-80 & 911 \\ 80-90 & 1028 \\ 90-98 & 1305 \\ 98-100 & 1734\end{array}$

Source: Fullerton and Rogers (1993)

This distribution has a mean of $\$ 738,310$ and a median of $\$ 665,000$ (implying a mean to median ratio of approximately 1.1), and a variance of log income equal to .17 . Note that relative to a distribution of annual household income (with a typical ratio of mean to median of 1.2 and variance of log income of approximately $.36)$, this distribution displays less variance.

In the theory section we considered preferences that had the characteristic that the slope of indifference curves (in the relevant price and $q$ space) were increasing in income. Anticipating our calibration, we often focused on preferences of the form $\frac{c^{\alpha}}{\alpha}+A \frac{q^{\gamma}}{\gamma}, \alpha<0$. In our simulations we further restrict this class of preferences by imposing $\alpha=\gamma$, i.e., we impose an income elasticity of one. The motivation for this restriction comes from an examination of longer-run trends in education spending. Over the last twenty-five years, spending on $\mathrm{K}-12$ education as a fraction of personal income has remained roughly constant despite roughly a doubling of real personal income. ${ }^{17}$ In our model, for all the education finance systems we considered, the requirement that a proportional shift in the income distribution (holding fixed the education finance system) keep constant the share of income spent on education requires that preferences be homothetic. If one

\footnotetext{
${ }^{17}$ See Fernandez and Rogerson (1997b) for an examination of this issue. This fact is, of course, distinct from the issue of how spending on education varies cross-sectionally with income.
} 
furthermore imposes separability, it requires that preferences be of the above form with $\alpha=\gamma .^{18}$

With the above specification of preferences, there are only two parameters to choose, $A$ and $\alpha$. For any given finance system, total resources spent on education are increasing in the parameter $A$. We choose $A$ so as to generate a "reasonable" share of total income devoted to education. For US states, the ratio of expenditures on $\mathrm{K}-12$ education to personal income ranges from around $3.2 \%$ to $6.2 \%$. We set $A$ such that the share of total income devoted to education under a foundation system is $5 \%$. We choose the foundation system as our benchmark system for the calibration exercise since we think it probably best approximates the "average" existing system. As discussed in our sensitivity analysis, however, our results are not sensitive to choosing other values for the expenditure share within this range, or to choosing a local system as the benchmark.

How to determine the value of $\alpha$ is less obvious. The additional restriction imposed in (2.2) of a non-positive value of $\alpha$ is motivated by theoretical and empirical considerations. On the theoretical front, as shown in the previous section, in a State system preferred state income tax rates are non-decreasing in income only if $\alpha$ is non-positive. Moreover, in a PER system, education expenditures would be negatively correlated with income if $\alpha$ were positive. To us, this suggests that requiring $\alpha$ to be non-positive is a reasonable restriction. ${ }^{19}$ On the empirical front, we consider three pieces of information. First, Fernandez and Rogerson (1995a) model California's pre-Serrano system as a foundation system and find that $\alpha=-.2$ does the best job of fitting the distribution of expenditures across districts. Second, the parameter $\alpha$ has implications for the price elasticity of education expenditures. In a survey of the empirical literature that attempts to estimate this elasticity, Bergstrom, Rubinfeld and Shapiro (1982) report a range of estimates between -0.5 and $-0.25 .{ }^{20}$ These imply values of $\alpha$ between -2 and -1 . Finally, under a foundation system, as described in more detail below, the value of $\alpha$ influences the cross sectional distribution of education spending across districts. One statistic that captures this is the cross-sectional elasticity of edu-

\footnotetext{
${ }^{18}$ Equilibrium allocations, of course, are unaffected by monotone transformations of the utility function

${ }^{19}$ Additionally, in a richer model with endogenous stratification of income types into communities, this condition is required to ensure that richer communities have higher quality education. See, for example, Westhoff (1977) and Fernandez and Rogerson (1996).

${ }^{20}$ One qualification that should be noted about these estimates is that they come from data on total spending and marginal tax prices. In systems with substantial amounts of aid given inframarginally this may seriously bias those estimates.
} 
cation spending with respect to district-level income. There is a large literature that estimates this elasticity, and though the range of estimates is substantial, the vast majority lie between .4 and .8 (see Bergstrom et al. (1982) for a survey of these estimates). As shown below, this suggests that $\alpha$ lies between 0 and -2 . In light of this information, we calibrate our benchmark model to $\alpha=-1$, and in our sensitivity analysis we examine $\alpha$ values between 0 and -3 .

In light of the discussion above, henceforth preferences will be described by:

$$
\frac{c^{\alpha}}{\alpha}+A \frac{q^{\alpha}}{\alpha} A>0, \alpha \leq 0
$$

\subsection{Calibration Results}

In this section we report the results of our calibration. Table 2 summarizes several features of the allocations generated by each of the education finance systems.

Table 2

$$
\text { Comparison of Systems, } \alpha=-1
$$

LOCAL STATE FOUND PER PEN

$\begin{array}{cccccc}\mathrm{E} / \mathrm{Y} & .048 & .046 & .050 & .049 & .057 \\ \mathrm{CV} & .41 & 0 & .35 & .20 & .25 \\ 95: 5 & 3.68 & 1.00 & 2.48 & 1.86 & 2.11 \\ \varepsilon_{q y} & 1.00 & 0.00 & .71 & .48 & .54\end{array}$

For each system, Table 2 reports the fraction of total income devoted to education $(E / Y)$, the coefficient of variation of spending across students $(\mathrm{CV})$, the ratio of spending per pupil at the 95th percentile relative to that at the 5th percentile (95:5), and the cross-sectional elasticity of education spending with respect to income $\left(\varepsilon_{q y}\right) .{ }^{21}$ Not reported in the table are the power equalizing factors (the $z$ 's) for PER and PEN. These are 1.08 and 1.40 times mean income, respectively. As mentioned previously, under $\operatorname{PER} z_{R}=z^{*}$ requiring a state tax of zero, whereas under PEN a state-level income tax rate of $\tau_{N}=.015$ is required to fund the power equalizing system.

\footnotetext{
${ }^{21}$ This elasticity is the regression coefficient on log income that results from regressing $\log$ of education spending on a constant and log income.
} 
There is substantial variation across systems in both total resources and the distribution of resources across students. For example, the highest spending system (PEN) generates almost $25 \%$ more spending on education than does the lowest spending system (State). And even excluding the State system, which by definition provides equal resources to all students, the system with the most inequality (local) has a coefficient of variation that is nearly double the corresponding figure for the PER system.

Note that $\varepsilon_{q y}$ is equal to one for the local system. This follows directly from the restriction on preferences that allows the model to match the longer-run data. Under a local system, homothetic preferences imply that each district allocates the same fraction of income to education. In the cross section, therefore, education spending and income move one for one in percentage terms. This also implies that under local finance the coefficient of variation is the same for the distribution of education spending across districts as for the distribution of income across districts.

Given that these systems yield large variations in both total resources and the distribution of resources across students, it is natural to ask whether the choice of system can be portrayed as a simple trade-off between resources and equity. For example, the local system provides more resources than does the State system, but also generates much greater inequality in resources per student. The results in Table 2 show, however, that there is no simple trade-off. In particular, the relationship between resources and inequality is not monotone-in fact, the two systems with intermediate amounts of inequality (foundation and PEN) generate the greatest resources allocated to education.

Table 3 below examines in more detail how the allocation of education spending varies across districts under the different finance systems. The table gives the entire profile of education resources (relative to economy-wide mean income) by district. This information is also presented in Figure 1, which illustrates the distribution of education resources by percentile group. 
Table 3

\begin{tabular}{cccccc}
\multicolumn{6}{c}{ Distributions of Education Spending $\alpha=-1$} \\
Income Pct. & LOCAL & STATE & FOUND & PER & PEN \\
$0-2$ & .0142 & .0460 & .0340 & .0279 & .0314 \\
$2-10$ & .0232 & .0460 & .0340 & .0354 & .0398 \\
$10-20$ & .0284 & .0460 & .0340 & .0390 & .0439 \\
$20-30$ & .0337 & .0460 & .0342 & .0424 & .0477 \\
$30-40$ & .0370 & .0460 & .0374 & .0443 & .0499 \\
$40-50$ & .0435 & .0460 & .0437 & .0479 & .0540 \\
$50-60$ & .0481 & .0460 & .0481 & .0502 & .0566 \\
$60-70$ & .0533 & .0460 & .0531 & .0527 & .0594 \\
$70-80$ & .0596 & .0460 & .0593 & .0556 & .0627 \\
$80-90$ & .0673 & .0460 & .0667 & .0589 & .0665 \\
$90-98$ & .0854 & .0460 & .0842 & .0659 & .0841 \\
$98-100$ & .1135 & .0460 & .1113 & .0753 & .1118 \\
$E / Y$ & .0483 & .0460 & .0500 & .0493 & .0568 \\
$C V$ & .41 & 0 & .35 & .20 & .25
\end{tabular}

One way of contrasting the different spending patterns is by examining the extent to which the different education finance systems achieve greater equality by "leveling up" or "leveling down" relative to the most unequal distribution-that generated by the local system. It should be kept in mind (and we will return to this in the welfare section), however, that we are not examining the cost involved in increasing the equality of education resources (e.g., the extent to which taxes are borne by the poor or by the rich). Thus, greater resources for education does not imply an increase in welfare.

The foundation and PEN systems achieve greater equality primarily by leveling up. To see this, note that for the top $30 \%$ of the population all three systems (local, PEN and foundation) deliver basically the same resources. However, foundation provides significantly more resources to the bottom $20 \%$ of the population than does local, and PEN provides significantly more resources than local to the bottom $70 \%$ of the income distribution. In contrasting foundation and PEN, note that foundation provides more resources to the bottom $2 \%$ of the income distribution, whereas PEN provides substantially more to everyone else below the 80th percentile. So, while it is true that foundation and PEN both involve leveling up relative to the local system, the mechanics of this leveling up differ significantly between the two systems. 
State and PER, in contrast, achieve greater equality through a combination of leveling up and leveling down, with the difference between the two being that State implies a much greater degree of compression. In particular, while State provides fewer resources for education for the top $50 \%$ of the income distribution than any of the other systems, it also provides more resources than all other systems for the bottom $40 \%$. Under PER, the bottom $60 \%$ of the distribution receive substantially more resources than under a local system, whereas the upper $30 \%$ all receive substantially less.

Contrasting PER with foundation, one observes that while the foundation system provides more resources to the very poorest $2 \%$ and the richest $40 \%$ of the population than does the PER system, the latter provides more educational resources to the remaining $58 \%$ of the population. PEN, on the other hand, provides more educational resources to all income groups than PER.

\subsection{Welfare Analysis}

In this section we examine the welfare implications of the five different finance systems. Of course, in economies with heterogenous agents and without lumpsum transfers, welfare comparisons pose some difficulty since any aggregate welfare measure depends on the weight placed on the utilities of different agents. With this caveat in mind, we carry out the following "behind-the-veil-of-ignorance" welfare comparison. For each system, we compute the expected utility that an agent would obtain if, under that system, her income were a random draw from the actual income distribution. Note that this welfare criterion is equivalent to a utilitarian welfare function (i.e., one that places equal weight on all agents' utilities).

We provide a measure of welfare differences which is not affected by affine transformations of the utility function. Using the foundation system as the benchmark for our utility comparison, we compute the factor $(1+\Delta)$ by which the entire income distribution would have to be scaled in the foundation system in order for the expected utility in that system to equal the level obtained under the alternative $j$ (where $j$ is local, State, PER, or PEN). ${ }^{22}$ That is, we solve:

$$
E U_{F}(\Delta) \equiv \sum_{i}\left[\frac{\left(\left(1-\tau_{f}-t_{i}\right) y_{i}(1+\Delta)\right)^{\alpha}}{\alpha}+A \frac{\left(\left(t_{i} y_{i}+f\right)(1+\Delta)\right)^{\alpha}}{\alpha}\right] f\left(y_{i}\right)=E U_{j}
$$

\footnotetext{
${ }^{22}$ See also Fernandez and Rogerson (1998b).
} 
yielding:

$$
1+\Delta=\left(E U_{j} / E U_{F}(\Delta)\right)^{1 / \alpha}
$$

The district tax rates in expression (3.2) are those from the foundation system. It should be noted here that, given (3.1), the district and state tax rates in the foundation system are invariant to proportional increases in the income distribution.

Table 4 displays the results of our welfare comparisons.

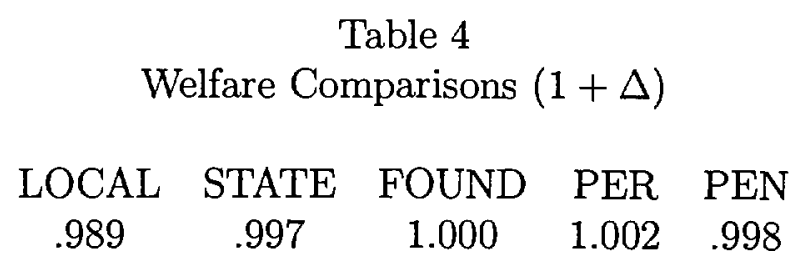

An immediate result from Table 4 is that the local system is dominated by all the other education finance systems (note that a value of $1+\Delta$ greater than one indicates that agents obtain a lower expected utility under a foundation system than under the alternative). We emphasize that any welfare gain over the local system in particular does not reflect efficiency gains ex post (i.e., once agents' identities or income levels have been determined); the allocation generated by the local system is in fact Pareto efficient in this sense. Rather, these gains reflect the fact that resources are being reallocated from wealthier to less wealthy individuals or equivalently, that the variance of the consumption and quality of education distributions are being diminished. These gains are weighed against the fact that each of the systems introduces some distortion into the economy. Table 4 allows us to conclude that relative to a system without any redistribution (i.e., the local system) the benefits from the redistribution implicit in the other four systems outweigh the costs of the distortions in every case.

The main conclusion from Table 4 is that PER dominates all systems whereas the foundation system dominates the local, State, and PEN system. It is of interest to note that although PEN offers greater educational resources to all individuals than does PER, it is nonetheless dominated by PER. This is because of the cost of financing PEN. Whereas under PER the tax base chosen implies a state tax rate of zero, all tax bases under PEN imply a positive state tax.

It should be noted that the welfare differences are not particularly large-PEN and State, for example, differ by .1\% of total income. This is due in part to the 
fact that education comprises only $5 \%$ of income-if we were to scale our welfare differences in proportion to the size of the education sector, then the difference between, for example, PER and local is more than $25 \%$ of the size of the education sector! ${ }^{23}$

\subsection{Determining the Choice of Finance System by Majority Vote}

Table 5 reports the majority voting outcomes across systems. To read the table, note that the row and column headings report which two systems are being compared under pairwise voting, with the entry in the corresponding box reporting which system wins. As the table indicates, the power equalizing system with recapture (PER) wins against all alternatives and the foundation system beats all alternatives except PER. Local loses to all alternatives. Thus, perhaps somewhat surprisingly, both our "behind-the-veil-of-ignorance" welfare criteria and majority voting yield the same outcome-PER is the preferred system.

Table 5

\begin{tabular}{cccccc}
\multicolumn{7}{c}{ Table 5} \\
\multicolumn{7}{c}{ Voting Comparison, $\alpha=-1$} \\
LOCAL & LOCAL & STATE & FOUND & PER & PEN \\
STATE & - & STATE & FOUND & PER & PEN \\
FOUND & - & - & FOUND & PER & STATE \\
PER & - & - & - & PER & FOUND \\
PEN & - & - & - & - & PER \\
PEN & - & - & - & -
\end{tabular}

The popularity of PER is itself not surprising. By proposition 4, PER is preferred to a State system. Furthermore, recalling that for our calibration we obtain $z_{R}=z^{*}$, propositions 5 and 8 imply that PER is majority preferred to a local, foundation or PEN system.

\section{Sensitivity}

This section explores the robustness of our findings to alternative values of $\alpha$, alternative income distributions, and to relaxing the non-negative state tax rate constraint in PER. We also investigated (but do not report on the details) the

\footnotetext{
${ }^{23}$ Another factor underlying our small welfare numbers is that our analysis is static. See Fernandez and Rogerson (1997b, 1998b) for an analysis of why dynamic considerations may produce much larger welfare differences.
} 
sensitivity of our findings to using systems other than the foundation for calibration and to ratios of $E / Y$ in the neighborhood of $5 \%$. These were found to have no impact on our results.

\subsection{Alternative Values of $\alpha$}

As discussed earlier, empirical work suggests $\alpha$ values in the range between 0 and -2 . We chose $\alpha=-1$ for our benchmark calibration. In this subsection we examine other values of $\alpha$ and show that our main findings are not sensitive to its exact value within the range suggested by empirical work. Before presenting these results it is perhaps worthwhile to discuss briefly how changes in $\alpha$ affect key variables. Central to this is an understanding of how changes in $\alpha$ affect the preferred tax rates that govern redistribution. Table 6 is instructive in this regard.

Table 6

Preferred State Tax Rates, $\tau_{s}$, State System

$\begin{array}{cccccc}\text { Income Pct. } & \alpha=0 & \alpha=-.5 & \alpha=-1 & \alpha=-2 & \alpha=-3 \\ 0-2 & .043 & .032 & .026 & .022 & .020 \\ 2-10 & .043 & .037 & .034 & .030 & .028 \\ 10-20 & .043 & .039 & .037 & .034 & .033 \\ 20-30 & .043 & .042 & .040 & .038 & .037 \\ 30-40 & .043 & .043 & .042 & .041 & .040 \\ 40-50 & .043 & .046 & .046 & .046 & .046 \\ 50-60 & .043 & .047 & .048 & .048 & .048 \\ 60-70 & .043 & .048 & .50 & .051 & .052 \\ 70-80 & .043 & .050 & .053 & .055 & .056 \\ 80-90 & .043 & .052 & .056 & .059 & .061 \\ 90-98 & .043 & .056 & .062 & .069 & .072 \\ 98-100 & .043 & .061 & .071 & .082 & .088\end{array}$

This table shows, for different values of $\alpha$, the preferred state tax rates for each income group under a State system. Note that, for each $\alpha$, the value of $A$ is chosen so that total spending on education under a foundation system is equal to $5 \%$ of income, as in our benchmark calibration. As $\alpha$ increases in absolute value, the distribution of preferred tax rates spreads out; preferred tax rates decrease for individuals with income below the mean and the reverse happens for those with income above the mean (preferred tax rates for those in the 40-60th percentiles are relatively constant for $\alpha<-.5$ ). A similar "spreading-out" of preferences occurs under the foundation and power equalizing systems. 
With this in mind we next turn to an examination of how the equilibrium state tax rate $\tau_{j} j=s, f, R, N$ varies across systems with $\alpha$. For PER and PEN, alongside the tax rate we also report the equilibrium values of $z_{j}$ that result (these are reported as multiples of mean income).

Table 7

\begin{tabular}{ccccccc}
\multicolumn{4}{c}{ Dependence of $\tau_{j}$ on $\alpha, j=s, f, R, N$} \\
\multicolumn{1}{c}{ STATE } & FOUND & PER & \multicolumn{3}{c}{ PEN } \\
$\alpha=0$ & .043 & .043 & 0 & 1.00 & 0.000 & 0.00 \\
$\alpha=-.5$ & .046 & .037 & 0 & 1.05 & 0.014 & 1.29 \\
$\alpha=-1$ & .046 & .034 & 0 & 1.08 & 0.015 & 1.40 \\
$\alpha=-2$ & .046 & .031 & 0 & 1.11 & 0.015 & 1.42 \\
$\alpha=-3$ & .046 & .029 & 0 & 1.12 & 0.014 & 1.42
\end{tabular}

A few patterns emerge from Table 7. Note first that as $\alpha$ decreases the foundation grant falls (recall that the foundation grant is given by $\tau_{f} \mu$ ). Since the amount of leveling up that occurs in a foundation system relative to a local system is determined by the size of the foundation grant, one may expect smaller reductions in inequality relative to a local system as $\alpha$ decreases. Under the State system, the fact that the median voter's preferred tax rate is fairly constant (see Table 6) gives the result of a fairly constant state tax rate as $\alpha$ decreases. Under $\mathrm{PEN}$, there is a large switch in outcome associated with different values of $\alpha$. For values of $\alpha$ close to zero (not shown), the outcome under PEN is equivalent to a local system. Majority vote results in $z_{N}=0$, hence all districts tax only their own district income to obtain funds for education. For more negative values of $\alpha$, the value of $z$ increases at first dramatically (as the system jumps from a local outcome to a large value of $z$ ), and then stays more or less constant.

Table 8 provides the analogous information as in Table 2 for a range of values of $\alpha$. Note that $\alpha=0$ (i.e., $\log$ preferences) is a special case. For this specification of preferences all individuals have the same preferred district tax rates in the local system and the same preferred state tax rate in the State system. Moreover, these rates are equal. Thus the local and State system yield the same total resources to education, but with very different distributions since in the local system district spending is proportional to district income, whereas in the state system it is proportional to mean income. 
Table 8

Comparison of Systems

\begin{tabular}{|c|c|c|c|c|c|c|}
\hline & & LOCAL & STATE & FOUND & PER & PEN \\
\hline \multirow[t]{4}{*}{$\alpha=0$} & $\mathrm{E} / \mathrm{Y}$ & .043 & .043 & .050 & .043 & .043 \\
\hline & $\mathrm{CV}$ & .41 & 0 & .23 & 0 & .41 \\
\hline & $95: 5$ & 3.68 & 1.00 & 1.73 & 1.00 & 3.68 \\
\hline & $\varepsilon_{q y}$ & 1.00 & 0.00 & .38 & 0.00 & 1.00 \\
\hline \multirow[t]{4}{*}{$\alpha=-.5$} & $\mathrm{E} / \mathrm{Y}$ & .047 & .046 & .050 & .048 & .057 \\
\hline & $\mathrm{CV}$ & .41 & 0 & .32 & .13 & .22 \\
\hline & $95: 5$ & 3.68 & 1.00 & 2.20 & 1.51 & 1.88 \\
\hline & $\varepsilon_{q y}$ & 1.00 & 0.00 & .61 & .32 & .44 \\
\hline \multirow[t]{4}{*}{$\alpha=-1$} & $\mathrm{E} / \mathrm{Y}$ & .048 & .046 & .050 & .049 & .057 \\
\hline & $\mathrm{CV}$ & .41 & 0 & .35 & .20 & .25 \\
\hline & $95: 5$ & 3.68 & 1.00 & 2.48 & 1.86 & 2.11 \\
\hline & $\varepsilon_{q y}$ & 1.00 & 0.00 & .71 & .48 & .55 \\
\hline \multirow[t]{4}{*}{$\alpha=-2$} & $\mathrm{E} / \mathrm{Y}$ & .049 & .046 & .050 & .050 & .055 \\
\hline & $\mathrm{CV}$ & .41 & 0 & .37 & .26 & .30 \\
\hline & $95: 5$ & 3.68 & 1.00 & 2.79 & 2.29 & 2.50 \\
\hline & $\varepsilon_{q y}$ & 1.00 & 0.00 & .79 & .64 & .69 \\
\hline \multirow[t]{4}{*}{$\alpha=-3$} & $\mathrm{E} / \mathrm{Y}$ & .049 & .046 & .050 & .050 & .054 \\
\hline & $\mathrm{CV}$ & .41 & 0 & .38 & .29 & .32 \\
\hline & $95: 5$ & 3.68 & 1.00 & 2.96 & 2.54 & 2.73 \\
\hline & $\varepsilon_{q y}$ & 1.00 & 0.00 & .83 & .72 & .76 \\
\hline
\end{tabular}

A similar situation holds for PER. With log preferences, all individuals prefer the same $z_{R}$, yielding the (unconstrained) outcome of $z_{R}=\mu$ and hence a state tax rate of zero. Note that although the state tax rate is zero, the district tax rate chosen is the same as the state tax rate would be under a State system. Hence PER and State are identical for these preferences. Lastly, as discussed previously, the outcome of majority vote for log preferences under PEN yield a local system. Hence the aggregate, but not distributional implications for these four systems are the same. The foundation system, on the other hand, generates greater aggregate spending on education. To see why, note that the fact that all individuals with income below the mean share the same preferences under the State system implies 
that the median voter in the foundation system will impose the same state tax rate as under the State system. Thus, all individuals with income below the mean will obtain the same education funds as under the State system, but individuals with greater income will top up, yielding a greater $E / Y$ than under the State system.

Otherwise, with the exception of the $\alpha=0$ case, the patterns that emerge are the same for each of the values of $\alpha$ considered. The ranking of systems in terms of resources devoted to education, or the coefficient of variation of education spending across students is the same for all values of $\alpha$. Moreover, while the exact magnitudes of differences across systems do depend on the value of $\alpha$, these differences are very similar for $\alpha$ between -.5 and -2 . Qualitatively, as $\alpha$ becomes smaller in absolute value, differences in total resources across systems become somewhat larger and differences in distributions across students become somewhat smaller.

Turning next to the welfare comparisons, Table 9 displays the results for different values of $\alpha$.

\begin{tabular}{cccccc}
\multicolumn{7}{c}{ Table 9} \\
$\alpha$ & WOCAL & STATE & FOUND & PER & PEN \\
0 & .995 & .999 & 1.000 & .999 & .995 \\
-.5 & .992 & .998 & 1.000 & 1.001 & .997 \\
-1 & .989 & .997 & 1.000 & 1.002 & .998 \\
-2 & .984 & .995 & 1.000 & 1.004 & .998 \\
-3 & .979 & .992 & 1.000 & 1.005 & .998
\end{tabular}

Once again the results are not very sensitive to the value of $\alpha$ : except for $\alpha=0$, PER dominates all systems whereas the foundation system dominates the local, State, and PEN system for all values of $\alpha$. The discontinuity at $\alpha=0$ occurs since at this value all individuals with income below the mean are indifferent between PER and the foundation system, whereas individuals with income above the mean prefer the ability to top up available in the foundation system. All other majority vote results between systems are unchanged from what we reported in Table 4. For more negative values of $\alpha$, the welfare differences across systems are larger.

\subsection{Alternative Income Distributions}

As discussed earlier, which income distribution would be most appropriate to use in our calibration-lifetime income, annual income, or something in between-is 
unclear. We chose to calibrate to lifetime income, but here we report findings based on calibrating to the distribution of annual income. For this exercise we take a discrete approximation to a log-normal distribution. Whereas the lifetime income distribution implied a variance of $\log$ income equal to .17, we now set this parameter equal to .36. Table 10 reports some results for $\alpha=-1.0$. This value of $\alpha$ implies a value of $\varepsilon_{q y}$ equal to .70, which is almost identical to the corresponding value of .71 for the $\alpha=-1$ case with the lifetime income distribution.

Table 10

Comparison Using Annual Income, $\alpha=-1$

\section{LOCAL STATE FOUND PER PEN}

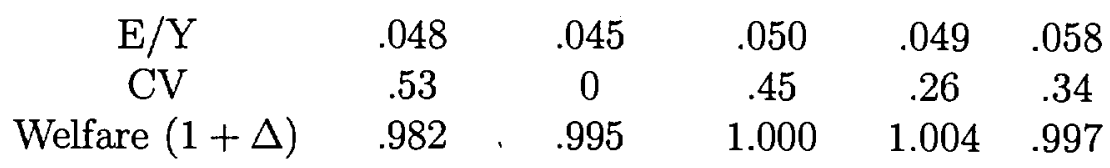

Basically, the results are very similar to those reported earlier. Relative to the calibration to lifetime income, all systems (save State) yield distributions of resources across students that have higher coefficient of variations. This reflects the increased variance of the underlying income distribution (recall that under local finance the distributions of income and spending have identical coefficient of variations). Furthermore, the range of spending and the welfare differences across systems increases. ${ }^{24}$

\subsection{PER With A Surplus}

Previously we restricted the PER system to non-negative values for $\tau_{R}$. This meant that the education finance system was not allowed to generate a surplus. In all of our simulations reported above, this constraint was binding-i.e., $\tau_{R}$ was always equal to 0 in equilibrium. How do our results differ if we remove this restriction and we allow the surplus to be rebated in proportion to income? Much of the conclusions remain the same with one exception-spending on education drops significantly. For example, for $\alpha=-1$, the reduction is about $12 \%$, making PER the system with the lowest resources devoted to education. Majority voting over

\footnotetext{
${ }^{24}$ We also explored the extent to which our results are affected by using a relatively coarse grid for the income distribution by trying out progressively finer discrete approximations to a log normal distribution. This had minimal effect on the results and hence is not reported.
} 
the power equalizing factor results in a value of $z_{R}$ equal to .86 times mean income, and everyone receives a rebate from the state government of more than $1 \%$. The reduction is spending is approximately uniform across the income distribution, as the coefficient of variation for education spending is roughly unchanged as a result of removing the restriction. Somewhat surprisingly, this drop in spending on education does not affect the welfare conclusions reported earlier. However, we think the main finding here is a cautionary note that if education finance systems are allowed to generate resources that can be used elsewhere, there is a definite danger that resources will be channeled away from education.

\section{Conclusion}

In this paper we used a political economy approach to analyze five different education finance systems. In addition to analytically characterizing the outcomes generated by each system, we also carried out a calibration exercise to assess the quantitative significance of the differences across systems. We found that the choice of system can have a very large impact on total resources allocated to education, as well as how those resources are distributed across students. A key finding is that the problem of choosing an education finance system from among this set cannot be portrayed as providing policy makers with a simple trade-off between equity and efficiency. With respect to generating spending on education, we find that this is done by those systems with intermediate degrees of redistribution. We also show that a power equalizing system with recapture (PER) yields the greatest social welfare (using a utilitarian welfare function) and that PER would be chosen above all the other systems were they subject to choice by majority vote.

Our model was purposefully simple in order to explore the trade-offs between equity and total resources to education, highlighting the fact that different incomes imply both different preferences and implicit prices for education across individuals and finance systems. This approach, unlike most of the other literature in this field, allowed us to obtain both analytical and quantitative results regarding the five finance systems. The next step would be to incorporate several other dimensions that would allow the model to capture other elements that may be important in reality. How robust are our results, to the existence of a private alternative. The model already gives some insight into this question. For example, a pure local system is equivalent to a system of private education and PEN can be interpreted as the outcome of a PER system with private options. 


\begin{abstract}
Alternatively, a foundation system can be interpreted as the outcome of allowing a voucher program with private alternatives under the State system. Another factor that should be examined is how the results would be modified by the existence of property (especially non-residential property) in a property-tax based system. Our majority vote analysis ignores any transition questions as there are no state variables in our analysis. The introduction of housing prices that vary with the education finance system would introduce winners and losers in dimensions other than that related to education resources. Other questions to be explored include imperfect stratification of individuals into communities, more complex political economy than that given by majority vote, and the dynamic implications of the different systems We leave these important explorations for future work.
\end{abstract}




\section{References}

[1] Benabou, R., "Workings of a City: Location, Education, and Production," Quarterly Journal of Economics 109 (1993), 619-652.

[2] _. Economic Review 86(3) (1996), 584-609.

[3] Bergstrom, T., D. Rubinfeld and P. Shapiro, "Micro-Based Estimates of Demand Functions for Local Public Expenditures," Econometrica 50 (1982), 1183-1205.

[4] Card, D. and A. Payne, "School Finance Reform, the Distribution of School Spending, and the Distribution of SAT Scores," NBER (Cambridge, MA) Working Paper No. 6766, 1998.

[5] Caucutt, B., "Education Policy When There are Peer Group Effects," mimeo, 1997.

[6] Coons, J., W. Clune III and S. Sugarman, Private Wealth and Public Education, Belknap Press of Harvard University, Cambridge, 1970.

[7] de Bartolome, C., "Equilibrium and Inefficiency in a Community Model with Peer Group Effects," Journal of Political Economy 98 (1990), 110-133.

[8] _What Determines State Aid to School Districts. A Positive Model of Foundation Aid as Redistribution," Journal of Policy Analysis and Management 16 (1997), 32-47.

[9] Downes, T. and M. Shah, "The Effect of School Finance Reforms on the Level and Growth of Per Pupil Expenditures," mimeo, Tufts University, 1994.

[10] Durlauf, S., "A Theory of Persistent Income Inequality", Journal of Economic Growth 1 (1), (1996), 75-93.

[11] Epple, D. and R: Romano, "Ends Against the Middle: Determining Public Service Provision When There are Private Alternatives," Journal of Public Economics 62 (1996a), 297-325.

[12] cal Economy 104 (1996b), 57-84. 
[13] "Competition Between Private and Public Schools, Vouchers, and Peer Group Effects," American Economic Review 88 (1998), 33-62.

[14] Evans, W., S. Murray and R. Schwab, "Schoolhouses, Courthouses and Statehouses after Serrano," Journal of Policy Analysis and Management 16(1), (1997), 10-37.

[15] _ _ _ "Education-Finance Reform and the Distribution of Education Resources," American Economic Review 88(4), (1998), 789-812.

[16] Fernández, R., "Odd versus Even: Comparitive Statistics in Multicommunity Models," Journal of Public Economics 65(2), (1997), 177-192.

[17] Fernández, R. and R. Rogerson, "Education Finance Reform and Investment in Human Capital: Lessons from California," NBER (Cambridge, MA) Working Paper No. 5369, 1995a.

[18] _ _ _ "On the Political Economy of Education Subsidies," Review of Economic Studies 62(2), (1995b), 249-262.

[19] _____, "Income Distribution, Communities and the Quality of Public Education," Quarterly Journal of Economics 111(1), (1996), 135-164.

[20] _ _ _ "Keeping People Out: Income Distribution, Zoning and the Quality of Public Education," International Economic Review 38(1); (1997a), $23-42$.

[21] ______, "Education Finance Reform: A Dynamic Perspective," Journal of Policy Analysis and Management 16(1), (1997b), 67-84.

[22] _ _ ___, "The Determinants of Public Education Expenditures. Evidence from the States, 1950-1990," mimeo, 1998a.

[23] _ _ _ _ " "Public Education and Income Distribution: A Dynamic Quantitative Evaluation of Education Finance Reform," American Economic Review 88 (1998b), 813-833.

[24] Fullerton, D. and D. Rogers, "Who Bears the Lifetime Tax Burden?," Brookings Institution, Washington, D.C., 1993. 
[25] Glomm, G. and R. Ravikumar, "Public versus Private Investment in Human Capital: Endogenous Growth and Income Inequality," Joumal of Political Economy 100 (1992), 813-834.

[26] , "Opting Out of Publicly Provided Services: A Majority Voting Result," Social Choice and Welfare 15(2), (1998), 187-199.

[27] Hamilton, B., "Zoning and Property Taxation in a System of Local Governments," Journal of Urban Studies 12 (1975), 205-211.

[28] Hoxby, C., "All School Finance Equalizations Are Not Created Equal," NBER (Cambridge, MA) Working Paper No. 6792, 1998.

[29] Inman, Robert P., "Optimal Fiscal Reform of Metropolitan Schools: Some Simulation Results," American Economic Review 68(1), (1978), 107-122.

[30] Loeb, S., "Estimating the Effects of School Finance Reform: A Framework for a Federalist System," mimeo,' 1998.

[31] Manwaring, R. and S. Sheffrin, "Litigation, School Finance Reform, and Aggregate Educational Spending," International Tax and Public Finance 4(2), (1997), 107-127.

[32] Meltzer, A. and S. Richard, "A Rational Theory of the Size of Government," Joumal of Political Economy, 89, (1981), 914-927. •

[33] Nechyba, T., "A Computable General Equilibrium Model of Intergovernmental Aid," Journal of Public Economics 62 (1996), 363-397.

[34] Poterba, J., "Demographic Structure and the Political Economy of Public Education," Journal of Policy Analysis and Management 16 (1997), 48-66.

[35] Roberts, K. "Voting Over Income Tax Schedules," Journal of Public Economics, 8, (1977), 329-340.

[36] Silva, F. and J. Sonstelie, "Did Serrano Cause a Decline in School Spending?", National Tax Journal 48 (1995), 199-215.

[37] Tiebout, C., "A Pure Theory of Local Expenditures," Journal of Political Economy 65 (1956), 416-424.

[38] Westhoff, F., "Existence of Equilibria in Economies with a Local Public Good," Journal of Economic Theory 14 (1977), 84-112. 
Distributions of Education Spending

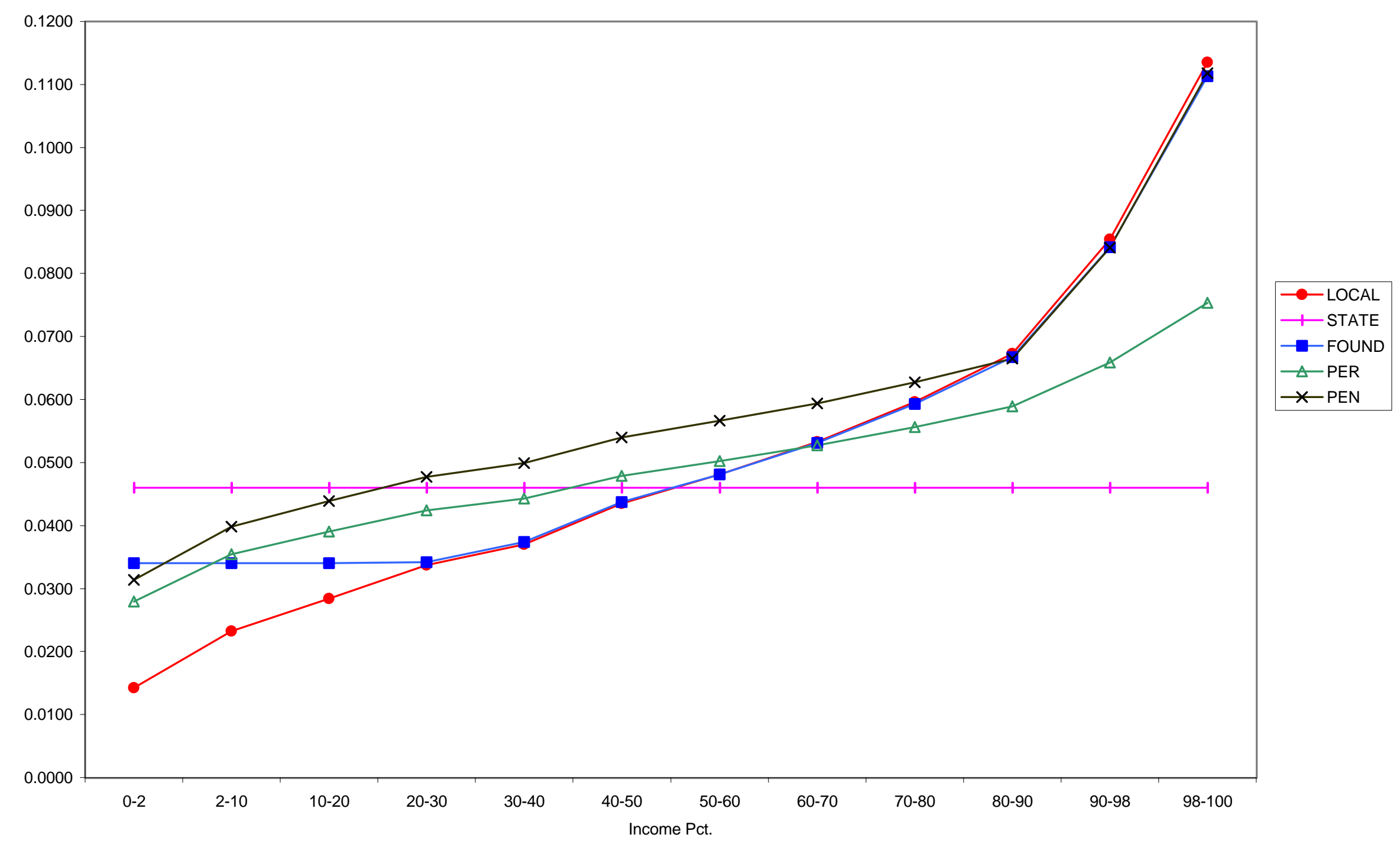

